\title{
Morphological and Molecular Identification of Fungi for their Association with Postharvest Fruit Rots in Some Selected Citrus Species
}

\author{
A. Jayasekara ${ }^{1}$, A. Daranagama ${ }^{1 *}$, T.D. Kodituwakku ${ }^{1}$ and K. Abeywickrama ${ }^{1}$ \\ Received: 17 th June 2021 / Accepted: 01 ${ }^{\text {st }}$ November 2021
}

\begin{abstract}
Purpose: The availability of fresh Citrus fruits is limited by their susceptibility to invasion by microbial pathogens which leads to cause serious postharvest losses. The present study was carried out to isolate and morphologically identify postharvest fungal associations from selected Citrus fruit species $(C$. sinensis, $C$. limon, C. crenatifolia and C. medica) and to confirm their identity by molecular characterization.
\end{abstract}

Research Method: Postharvest fungal associations of selected Citrus fruit species were isolated, and identification was done based on morphological characteristics. Confirmation of fungal associations was done through phylogenetic analysis of newly generated ITS sequencing data. Further, frequency of occurrence of each fungal isolate was calculated in three different districts in Sri Lanka.

Findings: From the morphological and molecular identification, Collectrichum fructicola, Collectrichum gloeosporioides, Lasiodiplodia theobromae, Aspergillus niger and Pestalotiopsis sp. were recorded from C. sinensis. Neofusicoccum parvum, Collectrichum gigasporium and Aspergillus clavatus were isolated from C. crenatifolia. Further, Lasiodiplodia theobromae and L. pseudotheobromae were the only fungal association isolated from $C$. limon and $C$. medica fruit species, respectively. It is worthwhile noting that this is the first report of association of the C. gigasporium and Pestalotiopsis sp. from Citrus fruits in Sri Lanka.

Research Limitations: Since this research was mainly focused on the isolation and identification of the potential fungal associations, pathogenicity evaluation could not be carried out.

Originality/value: Findings of potential disease causative agents in citrus will be valuable for agriculture sector, to adopt and practice effective strategies to minimize postharvest losses of citrus fruits.

Keywords: Citrus fruits, Fungal associations, Molecular identification, Postharvest fungi

\section{INTRODUCTION}

Citrus is the largest genus in the family Rutaceae and it is one of the most traded horticultural products in the world (Turner and Burri, 2013). Citrus fruits are native to the tropical and subtropical areas of Asia and later they spread to other parts of the world (Liu et al., 2012). Most of the citrus fruits are highly preferred as fresh juice and as a flavour enhancer in food (Herath et al., 2016). Due to the delicious taste and nutritional value it possesses, citrus has become one of the most desirable fruits in the local as well as international markets. Citrus fruits have higher contents of nutrients such as vitamin $\mathrm{A}$ and $\mathrm{C}$, sugars, minerals, and amino acids with beneficial properties for health such as antioxidant, anticancer and antimutagenic (Paul and Shaha, 2004; Herath et al., 2016).

Citrus sinensis (Green cultivar is locally known as "Pani dodam") is considered one of the most important fruit crops due to its sweet taste and other benefits such as nutritional and medicinal

\footnotetext{
${ }^{1}$ Department of Plant and Molecular Biology, Faculty of Science, University of Kelaniya, Kelaniya, Sri Lanka. anupamad@kln.ac.lk

(D) https://orcid.org/0000-0001-570416-8943
} 
values. It is more popular among consumers as a fresh juice due to its succulent nature (Shravan et al., 2018). C. limon ("Lemon") is commonly used in both home and commercial recipes as a food ingredient. Further, lemon acts as an excellent preventative medicine and it has a wide range of uses in the indigenous medicine as well (Chaturvedi and Shrivastava, 2016). C. crenatifolia (locally known as "Heen naran") is supposed to be native to Sri Lanka, which is well known for a wide range of medicinal properties, and has been used to treat vomiting, nausea and liver diseases.

The availability of fresh citrus fruits in the local and international markets have been limited by their susceptibility to physical, chemical, and pathological damages, causing serious postharvest losses. Any postharvest deterioration or decay may result in citrus fruits with an undesirable quality and a shortened storage life, thereby subjected to rejection of fruits in local and international trade (Al-Mouei, 2014). Citrus fruit loss has mainly been attributed to postharvest diseases caused by various pathogens which accounts for approximately $25 \%-30 \%$ of the total wastage in the world (Saroj and Ambadas, 2008). Citrus fruits are more susceptible to infections by microbial pathogens due to the high nutrient composition and readily available water content, during the period between harvest and consumption (Tripathi and Dubey, 2004). They are more prone to fungal deterioration since citrus fruits are acidic having a $\mathrm{pH}$ range of $2-4$. Anthracnose, stem end rot, sour rot, green and blue mold, brown rot, and Alternaria rot can be considered as common fungal diseases of citrus (Palou et al., 2001; Ladaniya, 2008).

Anthracnose is mainly caused by Colletotrichum gloeosporioides. However, Colletotrichum karstii, has also been reported to be involved in the infection and disease progress (Baroncelli et al., 2017). Anthracnose is a latent infection and symptoms appear as lesions that are irregular in shape and of various sizes (Timmer et al., 1998). Stem-end rot (SER) is known to be caused by a complex of fungal pathogens including Lasiodiplodia theobromae, Diaporthe citri, C. gloeosporioides and Phomopsis sp. These pathogens endophytically colonise during fruit development in the orchard or field and remain quiescent until the onset of fruit ripening. In advanced stages of ripening, SER progresses to decay resulting in heavy losses of citrus fruits (Galsurker et al., 2018). Citrus brown rot is caused by several Phytophthora species (P. palmivora, P. citrophthora, $P$. nicotianae, and $P$. hibernalis) while Geotrichum citri and Alternaria citri are supposed to be the main causal agents of sour rot and Alternaria rot respectively. Green and blue mold cause significant economic losses during fruit storage and marketing due to both Penicillium digitatum and P. italicum respectively (Papoutsis et al., 2019). Rind injuries and impact bruising are the major contributors to fruit deterioration, since they accelerate water loss, stimulate higher respiration and ethylene production rates, and help pathogen development. Postharvest diseases represent the major causes of postharvest losses in local and international markets. It contributes to the fruit waste in the marketplace and cause quality and safety losses of fruits throughout the supply chain, resulting in high economic loss (Negi and Anand, 2014). Consumers are reluctant to accept fruits of low quality resulting in decreases in export.

The availability of significant detailed research studies on the characterization of postharvest fungal pathogens from selected citrus fruit species in Sri Lanka, under both molecular and morphological aspects are comparatively low. Therefore, the main objective of this study was to isolate and identify the postharvest fungal pathogens commonly inhabiting selected citrus fruit species through both morphological and molecular parameters. An attempt was also made to assess the frequency of occurrence of the isolated fungi from the three districts viz. Colombo, Gampaha and Kandy in Sri Lanka.

\section{MATERIALS AND METHODS}

\section{Sample collection}

Citrus fruits (C. sinensis, $C$. crenatifolia, $C$. limon, C. medica) with visible symptoms of postharvest diseases were collected from different local markets in Kelaniya, Kiribathgoda, Kadawatha, Gampaha, Kegalle, Mawanella, 
Kadugannawa and Kandy areas in Sri Lanka. The collected samples were brought to the laboratory in sterile polythene bags with proper packing and labelling.

\section{Isolation of fungi}

Diseased citrus fruit tissues $\left(4 \mathrm{~mm}^{2}\right)$ were cut from margins of symptomatic areas under aseptic conditions. The tissues were surface sterilized by soaking the sections in freshly prepared $\mathrm{NaOCl}(3 \% \mathrm{w} / \mathrm{v})$ for 3 minutes. After 3 serial washings in sterile distilled water, citrus tissues were placed ( 2 pieces per plate) on sterile petri plates containing Potato Dextrose Agar (PDA) medium. Inoculated plates were incubated at room temperature $28 \pm 2{ }^{\circ} \mathrm{C}$ for 5 to 7 days. After incubation, pure cultures of the isolates were prepared by transferring $5 \mathrm{~mm}^{2}$ mycelial discs on to freshly prepared, sterile PDA plates. Colony characters of pure cultures grown on PDA plates were observed and recorded. The associated fungi were identified by observing their morphological characteristics such as conidial shape, hyphal septations, and other structures under Phase Contrast Microscope under $\times 400$ magnification (Olympus CX41 model, Tokyo, Japan) by comparison with Atlas of pathogens and relevant literature (Ploetz, 2003; Abeywickrama, 2006; Ekanayake et al., 2019).

\section{DNA extraction}

DNA was extracted from isolated fungal cultures grown on PDA plates using modified CTAB protocol (Daranagama et al., 2015). The total genomic DNA was extracted from $0.05-0.10 \mathrm{~g}$ of growing mycelium by scraping from the edge of the growing culture. Mycelium was ground with half volume of polyvinylpyrrolidone (PVP), sterile quartz sand and $200 \mu \mathrm{L}$ of pre-heated $\left(65{ }^{\circ} \mathrm{C}\right) 2 \%$ CTAB buffer in sterilized micro centrifuge tubes. $400 \mu \mathrm{L}$ of pre-heated $\left(65^{\circ} \mathrm{C}\right)$ CTAB buffer was added and incubated in 65 ${ }^{\circ} \mathrm{C}$ for 60 minutes. The tubes were centrifuged at $12000 \mathrm{rpm}$ for 10 minutes. The supernatant was treated with an equal volume of Phenol: Chloroform: Iso amyl alcohol $(25: 24: 1)$ and the solution was mixed by inversion. The tubes were centrifuged at $10000 \mathrm{rpm}$ for 10 minutes and the supernatant was transferred to fresh micro centrifuge tubes. An equal volume of Chloroform: Isoamyl alcohol (24:1) was added, mixed by inversion and tubes were centrifuged at 10000 rpm for 10 minutes. The upper aqueous phase containing DNA was transferred to fresh micro centrifuge tubes and an equal volume of ice-cold iso-propanol was added and incubated for 1 hour at $-20^{\circ} \mathrm{C}$. After the samples cooled down to room temperature, precipitated DNA was recovered by centrifugation at $12000 \mathrm{rpm}$ for 10 minutes followed by three steps of purification with $70 \%$ ethanol. The air dried, precipitate was dissolved in $25 \mu \mathrm{L}$ of nuclease free water and stored at -20 ${ }^{\circ} \mathrm{C}$ until use for amplification reactions.

\section{PCR amplification}

Extracted DNA was used for the amplification of ITS region using ITS 1 and ITS 4 primers (F- 5' CTTGGTCATTTAGAGGAAGTAA 3' and R- 5' CAGACTTGTACATGGTCCAG 3'). A total volume of $25 \mu \mathrm{L}$ reaction mixture [5X PCR buffer, $1.5 \mathrm{mM} \mathrm{MgCl}_{2}, 0.25 \mathrm{mM}$ $\mathrm{dNTP}, 0.4 \mu \mathrm{M}$ of each primer, Taq polymerase, and $1.0 \mu \mathrm{L}$ template DNA] was used for PCR with adjustments of components' volumes and concentration when needed. PCR was carried out in a thermal cycler (Veriti 96-Well Thermal Cycler, ABI Biosystems, USA) following initial denaturation at $95^{\circ} \mathrm{C}$ for 5 minutes, 37 cycles of denaturation at $95{ }^{\circ} \mathrm{C}$ for 30 seconds, annealing at $54{ }^{\circ} \mathrm{C}$ for 30 seconds, extension at $72{ }^{\circ} \mathrm{C}$ for 1 minute 30 seconds and final extension at $72{ }^{\circ} \mathrm{C}$ for 10 minutes (Daranagama et al., 2015).

\section{Agarose gel electrophoresis}

The agarose gel electrophoresis was carried out at $90 \mathrm{~V}, 300 \mathrm{~mA}$ and $60 \mathrm{~W}$ for 60 minutes in a horizontal gel electrophoresis system. Amplified PCR products were visualized in agarose gel $(1 \%)$ in $1 \mathrm{X}$ TBE containing ethidium bromide using gel documentation system (QUANTUM ST5, Germany). Hundred base pair ladder (Promega, USA) was used for quantification of the PCR products. 


\section{DNA sequencing of the isolated fungal strains}

Sequencing was performed at Genetech Pvt. Ltd., Colombo, Sri Lanka and Macrogen Inc. Seoul, Republic of Korea using the same primers for successful PCR products. Sequences obtained were manually edited using BioEdit sequence Alignment Editor (Version7.2.5). Sequences generated from this study were analyzed comparatively with other homologous sequences retrieved from GenBank by NCBI Blast search (https://www.ncbi.nlm.nih.gov/) (Table 01).

\section{Sequence alignment and phylogenetic analysis}

Sequence homologies for the assembled consensus sequences were analyzed using the BLAST search engine available at the NCBI for the initial identification of fresh isolates, used in the analyses. Newly generated sequences were aligned using MUSCLE (Multiple Sequence Alignments) Alignment tool of MEGA sequence Alignment Editor (Version 7.0) along with reference taxa of Lasiodiplodia, Aspergillus, Pestalotiopsis and Neofusicoccum species, obtained from the GenBank. The alignments were visually checked and manually improved where necessary. Phylogenetic analysis using Maximum Likelihood (ML) trees, was constructed using the MEGA software (Version 7.0). Kimura 2-parameter model with bootstrap values obtained for 1000 bootstrap replicates were applied following Kimura (1980). The best scoring tree was selected. Initial tree(s) for the heuristic search were obtained automatically by applying Neighbor-Joining and Bio NJ algorithms to a matrix of pairwise distances estimated using the Maximum Composite Likelihood (MCL) approach, and then selecting the topology with superior log likelihood value. Trees were constructed in MEGA (Version 7.0) software (Ekanayake et al., 2019).

\section{Frequency of occurrence of fungal isolates}

Research was conducted to investigate disease causative agents associated with four citrus fruit species from different markets in Gampaha, Kegalle, and Kandy Districts. Fungal associations isolated from each species and the number of isolates were recorded separately. Frequency of occurrence of each fungal isolate was calculated using the following equation (Tafinta et al., 2014; Muhammad et al., 2018).

\section{Frequency of occurrence $=$ \\ (Number of isolations of a particular pathogen in a corresponding disctrict)}

(Number of total isolations of pathogens in the corresponding district)

\section{RESULTS AND DISCUSSION}

\section{Isolation and purification of the isolated fungi}

Five fungal strains (CS 01, CS 02, CS 03, CS 04, and CS 05) were isolated and purified from spoilt C. sinensis while CC 01, CC 02 and CC 03 were recorded from C. crenatifolia fruits. Further, CL 01 was the only fungus isolated from $C$. limon whereas isolate CM 01 was recorded from $C$. medica. Identification of the isolated fungal strains was performed observing morphological characters and performing internal transcribed spacer (ITS) sequencing.

\section{Morphological identification of fungal isolates}

CS 01 and CS 02 were similar in appearance and grew rapidly on PDA medium. CS 01 isolate was in filamentous form at the beginning with white mycelium which turned yellowish to orange on maturity. Colony produced dark-orange pigments with production of conidia, which were immersed throughout the plate exhibiting circular rings (Figure 01.A). In CS 02, colonies contained cottony, creamy-white mycelia which formed concentric rings gradually on the PDA medium on maturity. The center rings attained a yellow colour with time. Colony produced numerous dark black acervuli on the culture plate with dark-orange pigmented mycelia in the center of the plate (Figure 01.C). Vegetative hyphae were hyaline, septate, smooth walled and branched. Conidia were hyaline, straight to cylindrical, and rounded at both ends in both CS 01 and CS 02 (Figure 01.B and D). 


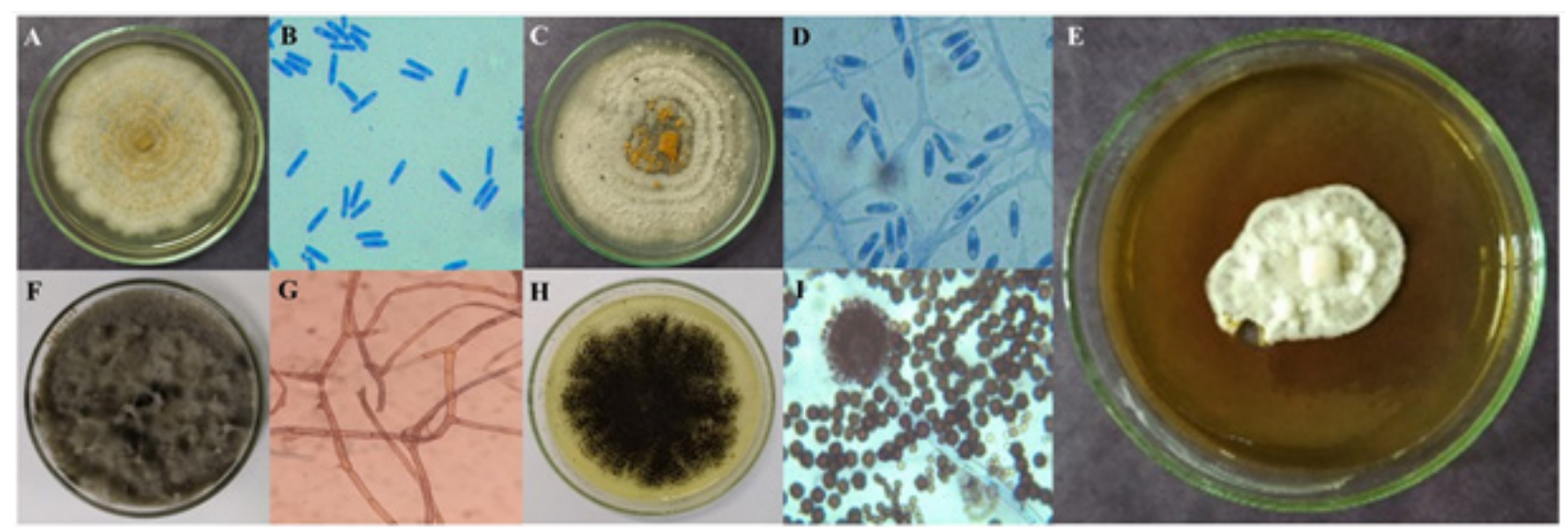

Figure 01: Morphological variation of fungal isolates (A, C, E, F and $\mathrm{H})$ from $C$. sinensis fruits and phase contrast microscopic view of $C$. fructicola with conidia (A and B), C. gloeosporiodes with conidia (C and D), Pestalotiopsis sp. grown on PDA (E), L. theobromae with mycelia (F and $\mathrm{G}), A$. niger with conidiophores and conidia (H and I).

In CS 03, colony grew very slowly on PDA and attained a diameter of $15-22 \mathrm{~mm}$ after 21 days of incubation. Colonies were white, wrinkled and the mycelia were thick and rough in texture (Figure 01.E). The reverse of the colony was orange in colour on PDA. CS 04 grew rapidly on PDA producing light grey, cottony, mycelia, which turned into dark grey within $2-3$ days (Figure 01.F). The hyphae were branched, septate and dark brown (Figure 01.G). During the period of study under laboratory conditions, no reproductive structures were visible.

The isolated colonies of CS 05 were wooly, initially being pale green and turned to black with the formation of conidia. The reverse of the colony was green to pale yellow. The edges of the colonies were pale yellow producing radial fissures (Figure 01.H). Hyaline and septate hyphae produced long erect conidiophores that became dark at the apex terminating in a globose vesicle. Carbon black conidia were arranged in chains (several rows) at maturity (Figure 01.I).

At the first appearance, CC 01 colony was white cottony to fluffy and with maturity ( $5-6$ days) turned to olivaceous grey. Culture grew rapidly on PDA producing moderately dense, light grey mycelia. The center of the colony attained a greyish yellow colour with time (Figure 02.A). The reverse of the colony was greyish yellow to black in colour. The hyphae were branched, septate and irregular in shape (Figure 02.B).
CC 02 colonies contained greyish green mycelia which formed concentric rings gradually on the PDA medium on maturity (Figure 02.C). The center rings attained dark brown colour with time. The reverse of the colony was yellowish brown in colour. Colony attained a filamentous form and powdery nature. Hyphae were branched, hyaline and aseptate (Figure 02.D). During the period of study under laboratory conditions, no reproductive structures were visible.

The isolated colony of CC 03 grew rapidly throughout the PDA plate and mycelia were initially grey and turned powdery black with sporulation (Figure 02.E). The reverse of the colony was greenish black. Hyphae were septate and hyaline with a long erect conidiophore that turned dark at the apex terminating in a globose vesicle. Black to dark brown conidia were arranged in columns (several rows) on the sterigmata at maturity (Figure 02.F and G).

The isolated CL 01 and CM 01 cultures were similar in appearance and they grew rapidly on PDA. Light grey, cottony, mycelia, which turned dark grey was observed on the PDA in both CL 01 and $\mathrm{CM} 01$ isolates (Figure 03.A and B). The reverse of the colony was dark grey/black in colour. The hyphae were branched, septate and dark brown in colour (Figure 03.C and D). During the period of study under laboratory conditions, no reproductive structures were visible. 


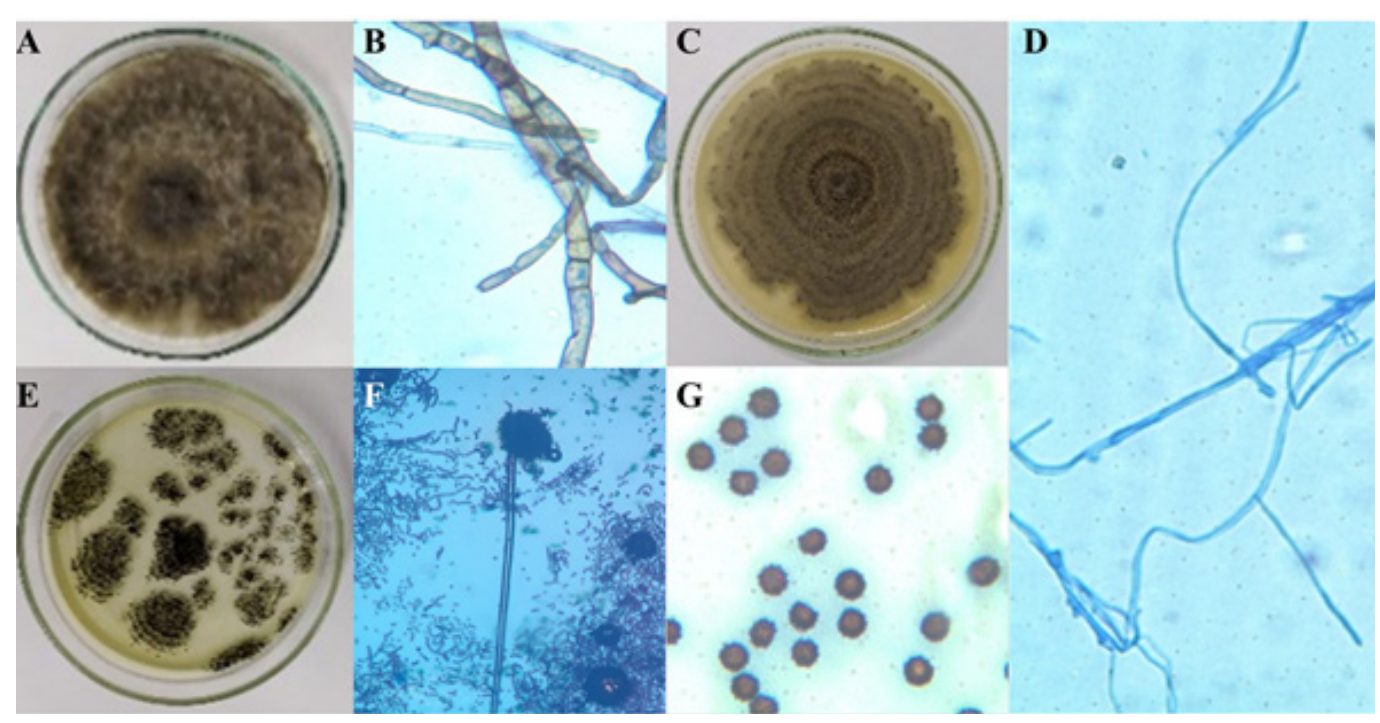

Figure 02: Morphological variation of fungal isolates (A, C and E) from C. crenatifolia fruits and phase contrast microscopic view of $N$. parvum with mycelia (A and $\mathrm{B}$ ), $C$. gigasporium with mycelia (C and D), A. clavatus with conidiophore and conidia (E, F and G).

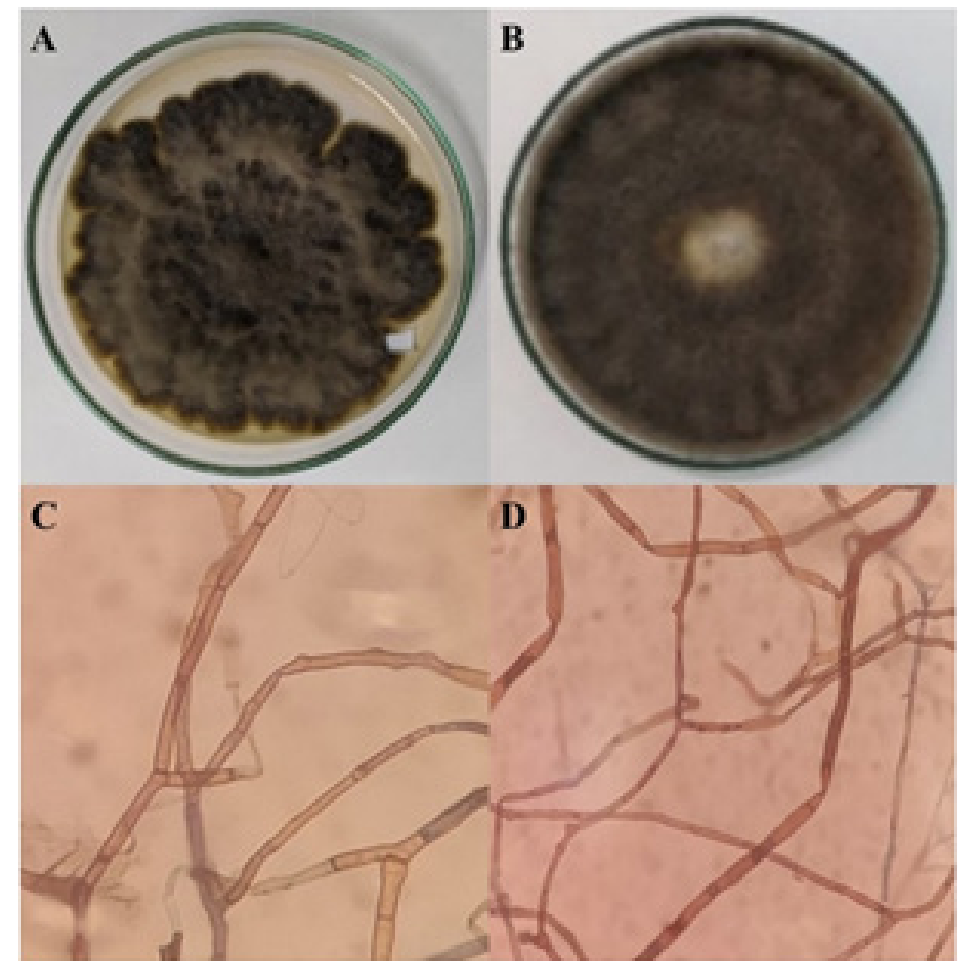

Figure 03: $\quad$ Phase contrast microscopic view of $L$. theobromae with mycelia (A and C) from $C$. limon and $L$. pseudotheobromae with mycelia (B and D) from $C$. medica

Based on the comparison of colony morphology, phase contrast microscopic micrographs and sporulation structures, both CS 01 and 02, were identified as Colletotrichum sp. whereas CS 04 and CS 05 isolated from C. sinensis were identified as., Lasiodiplodia sp. and Aspergillus sp. respectively. Further, CC 01 and $\mathrm{CC} 03$ isolated from $C$. crenatifolia were identified as Neofusicoccum sp. and Aspergillus sp. CL 01 isolated from $C$. limon and CM 01 isolated from C. medica were identified as Lasiodiplodia sp. However, CS 03 and CC 02 could not be identified morphologically as there were no reproductive structures visible during the time of study. 
Preliminary identification of the fungal isolates based on sequence data

According to the BLAST search performed, sequence analysis of the ITS regions exhibited significant sequence similarities for CS 01 (100 \%), CS 02 (99\%), CS 03 (99\%), CS 04 (98 $\%)$ and CS 05 (98\%) with previously reported Colletotrichum fructicola (MK611680.1), Colletotrichum gloeosporiodes (MT254840.1), Pestalotiopsis sp. (KU377578.1), Lasiodiplodia theobromae (LC074359.1) and Aspergillus niger (MK886749.1), respectively. ITS sequences of CC 01 (99\%), CC 02 (98\%) and CC 03 (100 $\%)$ showed sequence similarities with previously reported isolates of Neofusicoccum parvum (MH712271.1), Colletotrichum gigasporium (KF687724.1) and Aspergilus clavatus
(MT620752.1). Further, CL 01 and CM 01 exhibited a $98 \%$ and $100 \%$ sequence similarities with previously reported isolates of Lasiodiplodia theobromae (KY655203.1) and Lasiodiplodia pseudotheobromae (MT043794.1), respectively.

\section{Phylogenetic analysis}

Phylogenetic analyses were performed for the genera Lasiodiplodia, Aspergillus, Neofusicocum and Pestalotiopsis using the MEGA software (Version 7.0). However, phylogenetic analysis was not performed for the genus Colletotrichum as only the ITS sequence data were not sufficient for reliable resolution of the terminal taxa (Crouch et al., 2009). The bipartition trees generated are shown in Figures $04-07$.

Table 01: Details of the locally collected fungal isolates and comparison with previously reported isolates

\begin{tabular}{|c|c|c|c|c|c|}
\hline $\begin{array}{l}\text { Sample } \\
\text { code }\end{array}$ & $\begin{array}{c}\text { Accession } \\
\text { number } \\
(\text { GENBANK) }\end{array}$ & $\begin{array}{l}\text { Highest match with } \\
\text { NCBI database }\end{array}$ & $\begin{array}{l}\text { Location of } \\
\text { previous isolate }\end{array}$ & $\begin{array}{l}\text { Percentage } \\
\text { similarity }\end{array}$ & Reference \\
\hline CS 01 & MZ081366 & $\begin{array}{l}\text { Colletotrichum } \\
\text { fructicola } \\
\text { (MK611680.1) }\end{array}$ & China & $100 \%$ & Luo, 2020 \\
\hline CS 02 & MZ081368 & $\begin{array}{l}\text { Colletotrichum } \\
\text { gloeosporiodes } \\
\text { (MT254840.1) }\end{array}$ & China & $99 \%$ & Wang, 2020 \\
\hline CS 03 & MZ081371 & $\begin{array}{c}\text { Pestalotiopsis sp. } \\
\text { (KU377578.1) }\end{array}$ & China & $99 \%$ & Deng et al., 2018 \\
\hline CS 04 & MZ081369 & $\begin{array}{l}\text { Lasiodiplodia } \\
\text { theobromae } \\
\text { (LC074359.1) }\end{array}$ & India & $98 \%$ & Prathibha et al., 2015 \\
\hline CS 05 & MZ081370 & $\begin{array}{l}\text { Aspergillus niger } \\
\text { (MK886749.1) }\end{array}$ & Egypt & $98 \%$ & Bendary et al., 2019 \\
\hline $\mathrm{CC} 01$ & MZ081372 & $\begin{array}{l}\text { Neofusicoccum } \\
\text { parvum } \\
\text { (MH712271.1) }\end{array}$ & China & $99 \%$ & Deng et al., 2018 \\
\hline $\mathrm{CC} 02$ & MZ150510 & $\begin{array}{l}\text { Colletotrichum } \\
\text { gigasporium } \\
\text { (MZ150510) }\end{array}$ & China & $98 \%$ & Liu et al., 2014 \\
\hline $\mathrm{CC} 03$ & MZ081373 & $\begin{array}{l}\text { Aspergilus clavatus } \\
\text { (MT620752.1) }\end{array}$ & China & $100 \%$ & $\mathrm{Li}, 2020$ \\
\hline CL 01 & MZ081374 & $\begin{array}{c}\text { Lasiodiplodia } \\
\text { theobromae } \\
\text { (KY655203.1) }\end{array}$ & Brazil & $98 \%$ & Santos, 2017 \\
\hline CM 01 & MZ081375 & $\begin{array}{l}\text { Lasiodiplodia } \\
\text { pseudotheobromae } \\
\text { (MT043794.1) }\end{array}$ & Malaysia & $100 \%$ & Nisam et al., 2020 \\
\hline
\end{tabular}




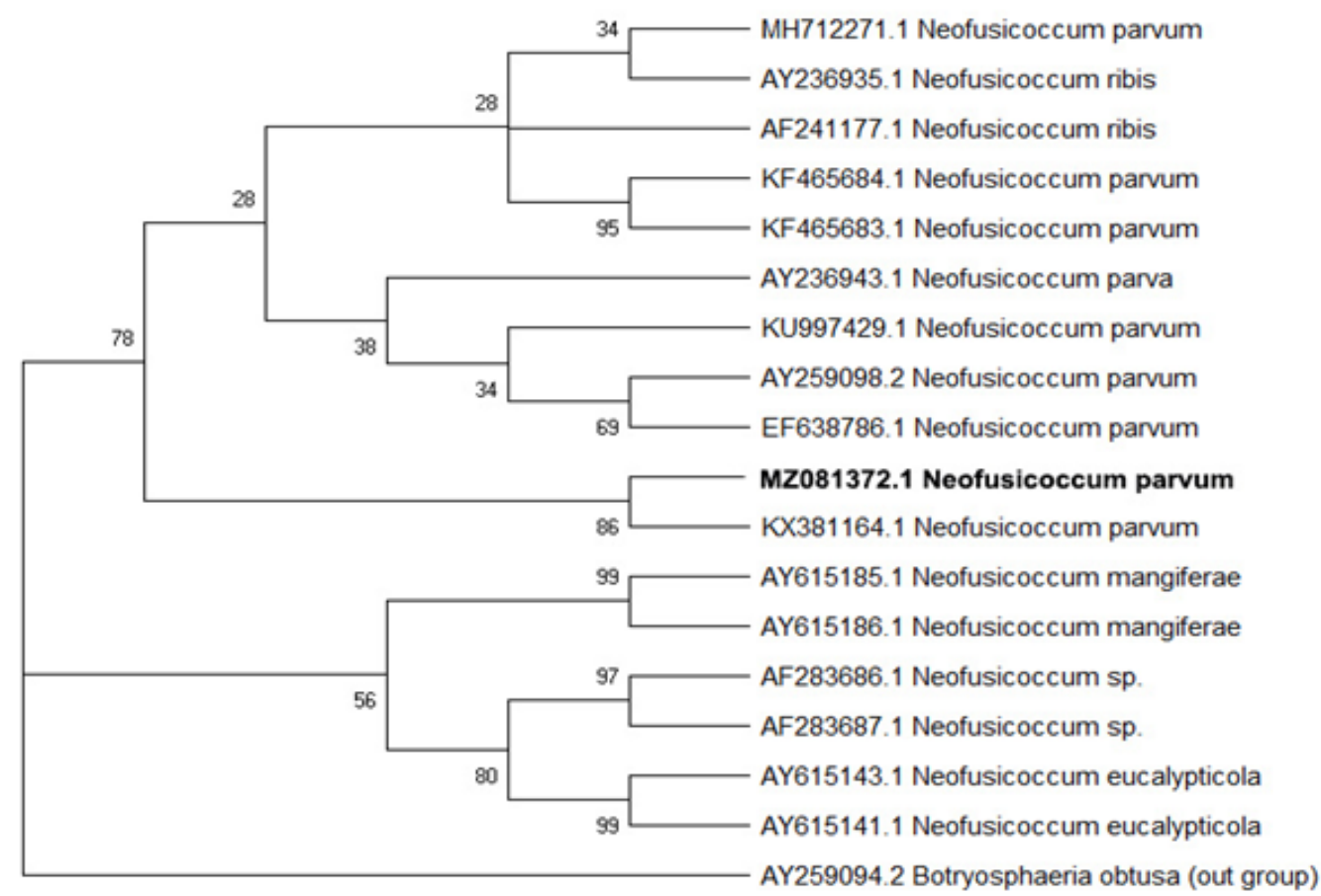

Figure 04: The phylogenetic tree of $N$. parvum (MZ081372.1) inferred from likelihood analysis using ITS sequences. Bootstrap values are given on the branches. The tree is rooted to Botryosphaeria obtusa (AY259094.2) (Lazzizera et al., 2008).

According to the phylogenetic analysis, the isolate CC 01 resulted from this study clustered with Neofusicoccum parvum (KX381164.1) with a high bootstrap support of $86 \%$, which identified as $N$. parvum (MZ081372.1). The subclade containing $N$. parvum (MZ081372.1) and $N$. parvum (KX381164.1) falls well within the main clade comprising other $N$. parvum strains with bootstrap support as high as $78 \%$ (Figure 04). Further, the isolate CS 03 appeared as a singleton within the main clade comprising many other Pestalotiopsis sp. Therefore, this isolate was identified as Pestalotiopsis sp. (MZ081371.1) (Figure 05).

The isolates CS 05 and CC 03 were identified to be Aspergillus sp. in the initial identification. During the phylogenetic analysis, CS 05 isolate clustered into a clade of $A$. niger with a high (83\%) bootstrap support, hence confirmed its phylogenetic position as A. niger (MZ081370.1). The other isolate CC 03 was identified as A. clavatus (MZ081373.1) (66 \% bootstrap support) which was clustered with several other A. clavatus species from different regions of the world (Figure 06).
The isolate CL 01 clustered with many strains of Lasiodiplodia theobromae with $66 \%$ bootstrap support, and was identified to be $L$. theobromae (MZ081374.1). Two isolates (CS 04 and CM 01 ) were identified as $L$. pseudotheobromae (MZ081369.1 and MZ081375.1) which formed a monophyletic clade with reference strains of L. pseudotheobromae. Isolate CS 04, clustered with L. pseudotheobromae with $72 \%$ bootstrap support while the isolate CM 01 clustered in this same clade with low bootstrap support of $18 \%$ (Figure 07).

From the phylogenetic trees generated, isolates clustered with reference sequences with bootstrap support of more than $70 \%$ were confirmed since clades with bootstrap support of more than 70 $\%$ are true for over $95 \%$ of the time with high accuracy and those with bootstrap values $>50 \%$ are considered probably significant (Hillis and Bull, 1993). The use of concatenated alignment of the ITS region with one or more of the proteincoding genes might have been effective for finer scale species-level identification of the specific fungi and might have accounted for higher resolution among species (Tekpinar and Kalmer, 2019). 


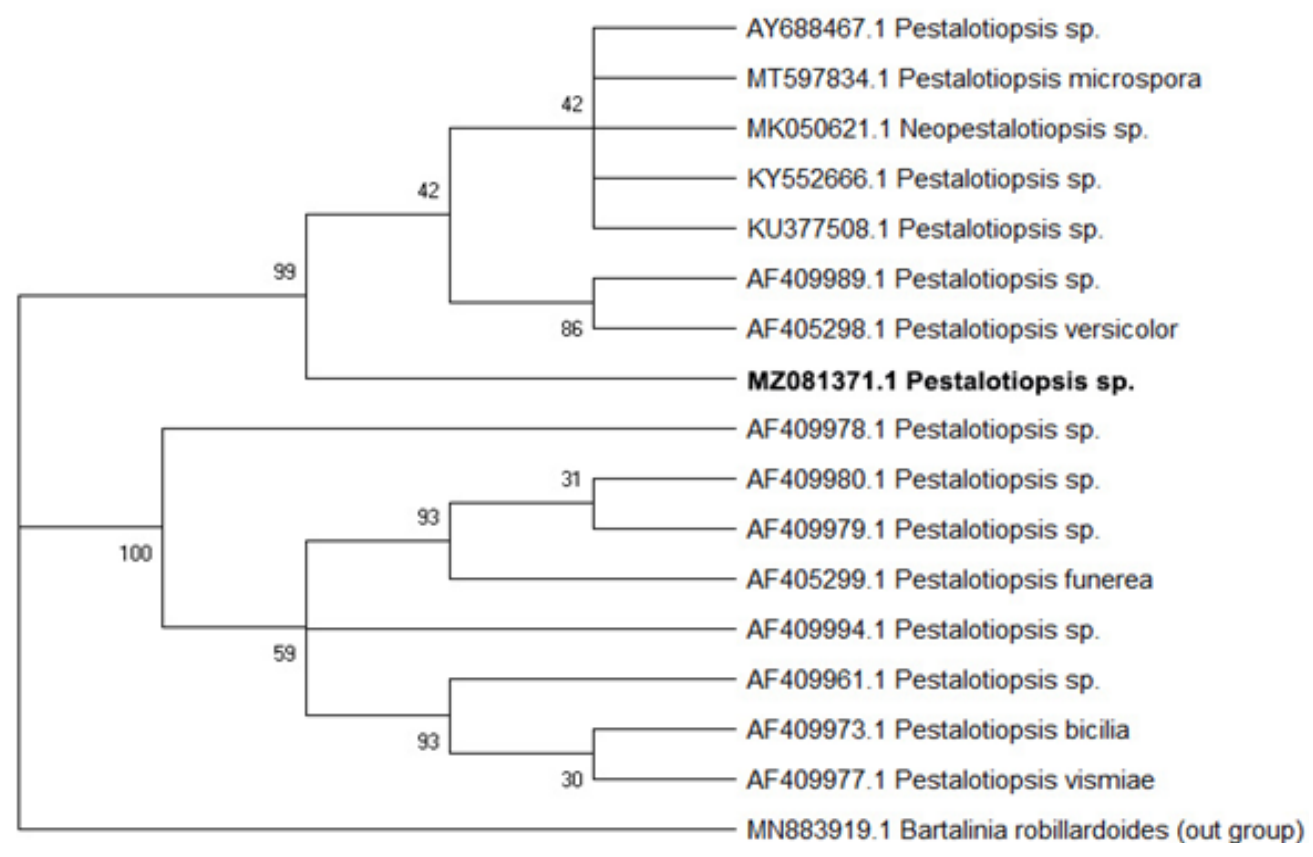

Figure 05: The phylogenetic tree of Pestalotipsis sp. (MZ081371.1) inferred from likelihood analysis using ITS sequences. Bootstrap values are given on the branches. The tree is rooted to Bartalinia robilardoides (MN883919.1) (Kamhawy et al., 2011).

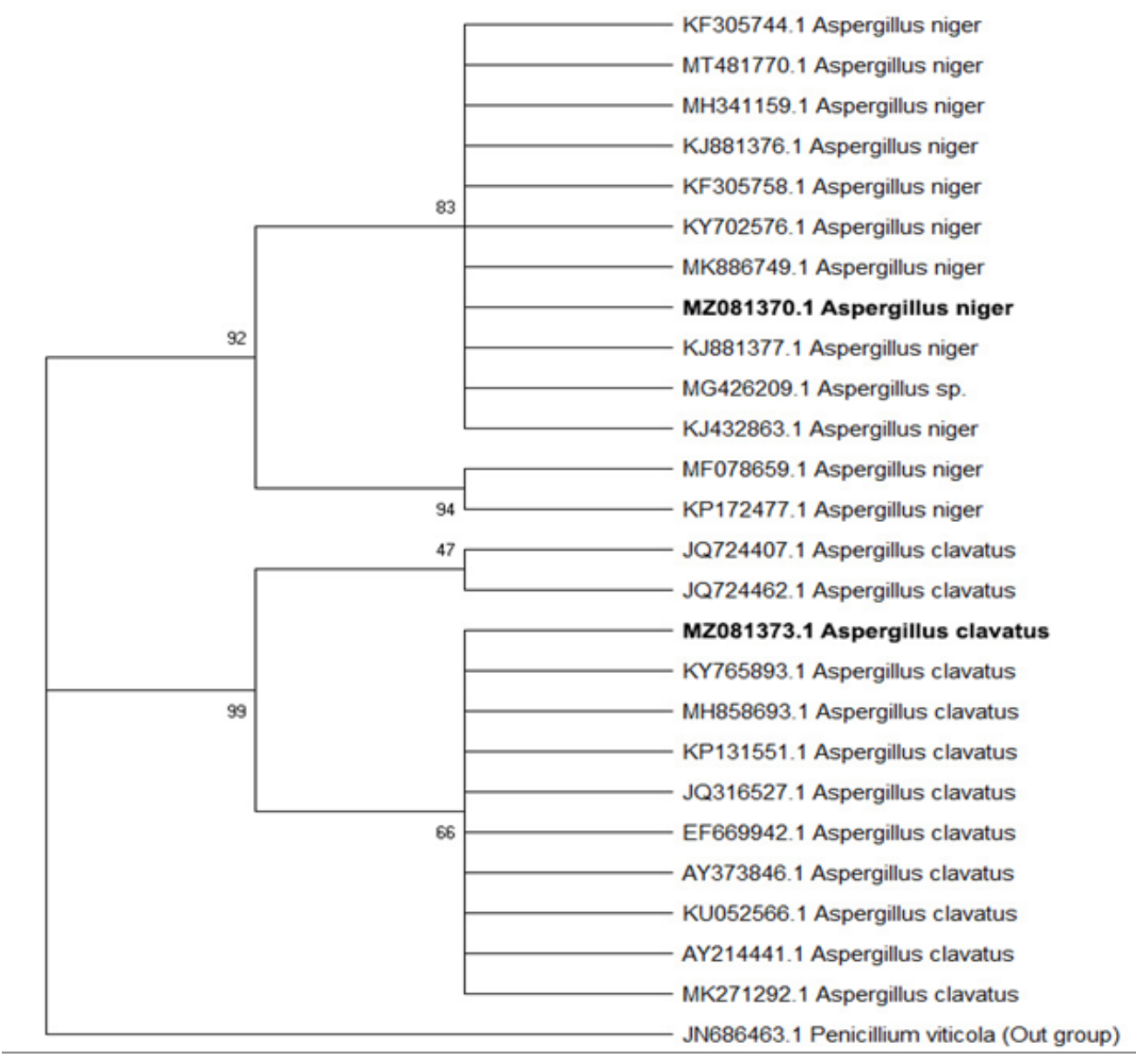

Figure 06: The phylogenetic tree of $A$. niger (MZ081370.1) and $A$. clavatus (MZ081373.1) inferred from likelihood analysis using ITS sequences. Bootstrap values are given on the branches. The tree is rooted to Penicillium viticola (JN686463.1) (Khan et al., 2019). 


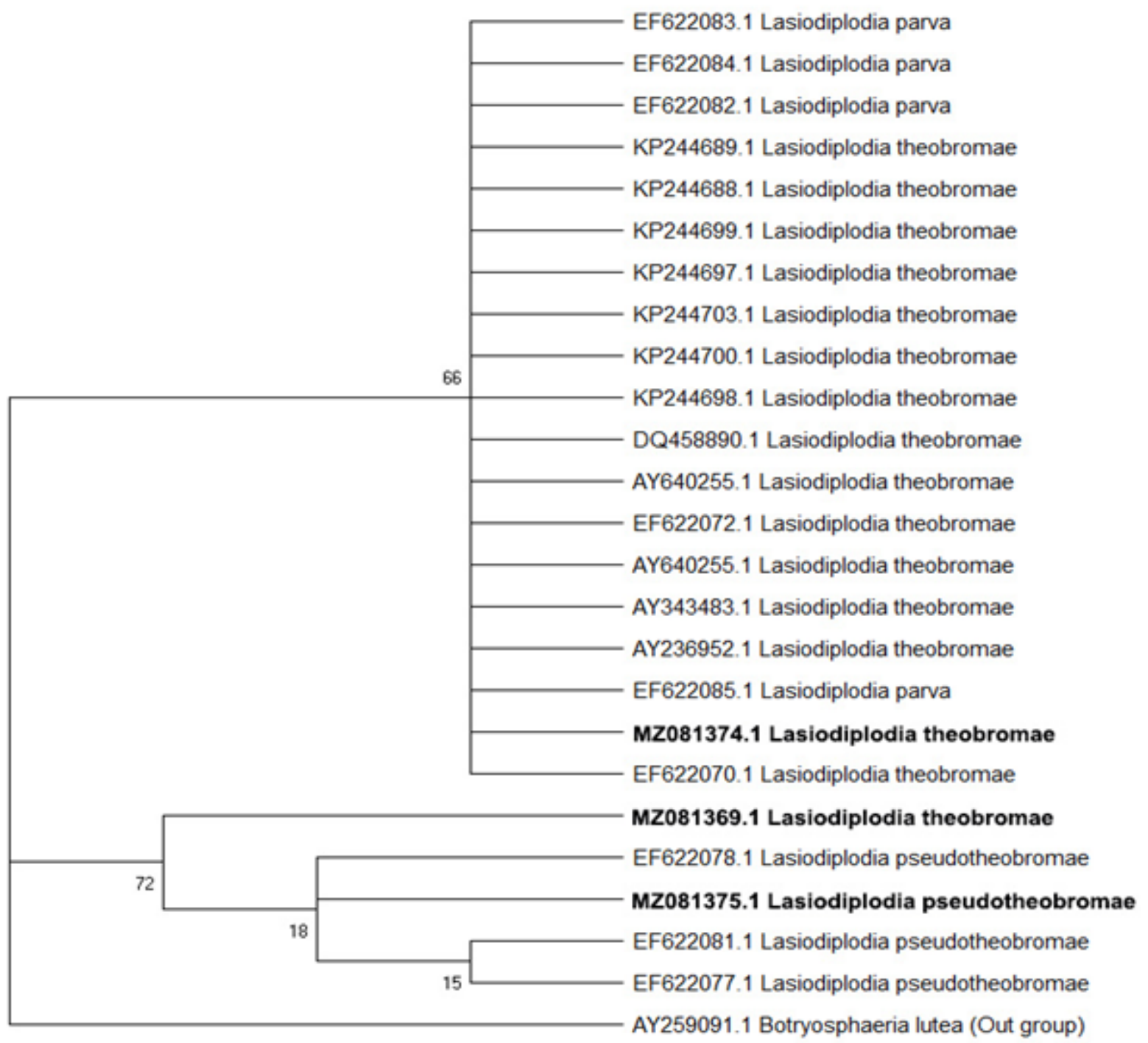

Figure 07: The phylogenetic tree of $L$. theobromae (MZ081374.1/MZ081369.1) and $L$. pseudotheobromae (MZ081375.1) inferred from likelihood analysis using ITS sequences. Bootstrap values are given on the branches. The tree is rooted to Botryosphaeria lutea (AY 259091.1) (Qian et al., 2014).

Frequency of occurrence and distribution of the fungal isolates

Based on the results, the isolated fungi from the spoilt citrus fruit species and their frequencies of occurrence are shown in Tables $02-04$. Lasiodiplodia theobromae, A. niger, N. parvum, A. clavatus and L. pseudotheobromae were the fungal strains isolated from the spoilt citrus fruits in the Kegalle District. Of the isolated fungi, $L$. theobromae isolated from the $C$. sinensis had the highest frequency of occurrence $(66.7 \%)$. $A$. niger isolated from $C$. sinensis and A. clavatus isolated from $C$. crenatifolia had the lowest frequencies of occurrence $(16.7 \%)$ indicating that they are less troublesome spoilage fungi on citrus. Lasiodiplodia pseudotheobromae which was isolated from $C$. medica recorded only from Kegalle District.

The results showed that the presence of a very interesting fungal biodiversity as there were eight fungal strains recorded from the three citrus species at different markets in the Gampaha District. Based on the fungal distribution, four strains (C. fructicola, C. gloeosporiodes,

L. theobromae and Pestalotiopsis sp.) were recorded from $C$. sinensis while three fungal strains ( $N$. parvum, $A$. clavatus and $C$. gigasporium) were recorded from $C$. crenatifolia. $L$. theobromae was the only fungus isolated 
from C. limon. Of the isolated fungi, N. parvum, isolated from $C$. crenatifolia had the highest frequency of occurrence $(75 \%)$ while three fungal strains (C. fructicola, Pestalotiopsis sp., and $C$. gigasporium) showed the lowest frequencies of occurrence $(13 \%)$.

Based on the data, a limited number of fungal strains could be isolated from three citrus species at different markets in the Kandy District. Of the isolated fungi, N. parvum isolated from $C$. crenatifolia had the highest frequency of occurrence (75\%) while L. theobromae isolated from $C$. limon had the lowest frequency of occurrence $(25 \%)$. Lasiodiplodia. theobromae and $C$. fructicola strains showed similar frequencies of occurrence $(50 \%)$. Based on the results of identified fungal strains, it can be concluded that $L$. theobromae, $C$. fructicola and $N$. parvum were recorded in all three districts. Lasiodiplodia theobromae was the only fungus isolated from $C$. limon in all three districts and the presence of $L$. pseudotheobromae was low in frequency. This could be attributed to less availability of $C$. medica variety in local markets which was found only from the Kegalle District.

According to the findings of previous research, many fungal strains have been identified from spoilt $C$. sinensis fruits. And similar fungal strains have been reported such as Colletotrichum sp., L. theobromae and A. niger. Further, A. flavus, A. fumigatus, $P$. chrysogenum, $P$. digitatum, Fusarium sp., and Alternaria sp. have been reported in spoilt $C$. sinensis fruits (Timmer et al., 1998; Tafinta et al., 2014; Muhammad et al., 2018). There have been no reports of pathogenic activities in Pestalotiopsis sp. related to postharvest diseases in citrus fruits. However, several previous studies have reported that Pestalotiopsis $\mathrm{sp}$. has been associated with crown rot disease of strawberry, stem-end rot disease of mango and fruit rot of grape (Deng et al., 2013; Ara et al., 2017; Kodituwakku et al., 2020). According to the best of the knowledge of the authors, this is the first report on the identification of Pestalotiopsis from selected citrus fruit species in Sri Lanka. In the present study, L. theobromae was the only fungus that was identified from the C. limon. However, many fungal strains have been reported as pathogens in previous studies such as C. gloeosporioides, A. alternata, A. citri, $P$. italicum, P. digitatum and Botrytis cinerea in C. limon (Kaur et al., 2020; Taha et al., 2019; Wang et al., 2021).

Three fungal strains were identified in $C$. crenatifolia such as $N$. parvum, C. gigasporium and A. clavatus in this research. Although the isolate of $C$. gigasporium has not been recorded related to postharvest diseases of citrus fruits, there is some evidence of $C$. gigasporium strain being associated with anthracnose disease in Avacado (Zakaria, 2021). Lasiodiplodia pseudotheobromae was the only fungi isolated from C. medica species in the present study. Furthermore, Rhizopus oryzae has been reported as the first isolated fungus in C. medica species (Manghwar et al., 2015). This may be the first report on the association of $L$. pseudotheobromae in $C$. medica fruits in Sri Lanka as no previous reports are available.

Isolated and characterized Colletotrichum sp. were recognized as causative agents of anthracnose disease and stem-end rot disease based on previous literature. Furthermore, $L$. theobromae has been known to be associated with stem-end rot disease in citrus fruits. The above two pathogens are considered as endophytes on a wide range of plant hosts and they have the ability to develop latent infections to become active during fruit ripening (Wang et al., 2021; Zhang, 2014;). Lasiodiplodia pseudotheobromae, N. parvum, and Aspergillus sp. have previously been identified as causative agents of fruit rot in citrus fruits (Chen et al., 2021; Zhai and Zhang, 2019). Aspergillus sp. are not considered as postharvest pathogens, however, as saprophytes they are responsible for significant postharvest losses of fruits.

\section{CONCLUSIONS}

Based on the morphological and molecular identification, the associated fungal strains, MZ081366, MZ081368, MZ081369, MZ081370, and MZ081371 which were isolated from spoilt C. sinensis were identified as C. fructicola, $C$. gloeosporiodes, Pestalotiopsis sp., L. theobromae, and A. niger respectively. Further, MZ081372, 
MZ150510 and MZ081373 were identified as $N$. parvum, C. gigasporium and A. clavatus in spoilt $C$. crenatifolia fruits. MZ081374 isolated from C. limon and MZ081375 isolated from $C$. medica were identified as $L$. theobromae and $L$. pseudotheobromae respectively. It is worthwhile noting that this is the first report on isolation and identification of $L$. pseudotheobromae from $C$. medica fruits as well as Pestalotiopsis sp. and $C$. gigasporium from citrus fruits. The findings need to be confirmed through pathogenicity studies to authenticate their pathogenic association with postharvest fruit rot of citrus fruits.

\section{ACKNOWLEDGEMENT}

Financial assistance provided by University of Kelaniya, Sri Lanka under the research grant:

$\mathrm{RP} / 03 / 02 / 01 / 01 / 2020$ is gratefully acknowledged.

\section{Conflicts of Interest}

The authors declare no conflict of interest.

\section{REFERENCES}

Abeywickrama, K. (2006). A pictorial guide to rapid and accurate identification of postharvest diseases of fruits. Godage International Publishers, Colombo, Sri Lanka. pp. 17-56.

Al-Mouei, R. (2014). Physiochemical juice characteristics of various citrus species in Syria. International Journal of Plant \& Soil Science, 3(9), pp. 1083-1095. https://doi.org/10.9734/ ijpss/2014/10505

Ara, T., Monzur, S., Saar, M., Islam, R., Alam, S. and Hossain, M. (2017). The first report of Pestalotiopsis sp. causing crown rot disease on strawberry (Fragaria X ananassa Duch.) in Bangladesh and evaluation of fungicide activity. International Journal of Biosciences (IJB), 11(4), pp. 350-358.http://dx.doi.org/10.12692/ijb/11.4.350-358

Baroncelli, R., Talhinhas, P., Pensec, F., Sukno, S., Le Floch, G. and Thon, M. (2017). The Colletotrichum acutatum species complex as a model system to study evolution and host specialization in plant pathogens. Frontiers in Microbiology, 8.https://doi.org/10.3389/fmicb.2017.02001

Chaturvedi, D., and Shrivastava, S.R. (2016). Basketful benefit of Citrus limon. International Research Journal of Pharmacy, 7(6), pp. 1-4.https://doi.org/10.7897/2230-8407.07653

Chen, J., Zhu, Z., Fu, Y., Cheng, J., Xie, J. and Lin, Y. (2021). Identification of Lasiodiplodia pseudotheobromae causing fruit rot of citrus in China. Plants, 10(2), pp. 202.https://doi. org/10.3390/plants 10020202

Crouch, J., Clarke, B. and Hillman, B. (2009). What is the value of ITS sequence data in Colletotrichum systematics and species diagnosis? A case study using the falcate-spored graminicolous Colletotrichum group, Mycologia, 101(5), pp. 648-656.https://doi.org/10.3852/08-231

Daranagama, D.A., Erio, C., Tian, Q., Liu, X., Chamyung, S., Stadler, M. and Hyde, K. D. (2015). Anthostomella is polyphyletic comprising several genera in Xylariaceae, Fungal Diversity, 73(1), pp. 203-238.https://doi.org/10.1007/s13225-015-0329-6

Deng, J., Sang, H., Hwang, Y., Lim, B. and Yu, S. (2013). Postharvest fruit rot caused by Pestalotiopsis sp. on grape in Korea. Australasian Plant Disease Notes, 8(1), pp.111-114. https://doi. org/10.1007/s13314-013-0109-7 
Ekanayake, G., Abeywickrama, K., Daranagama, A. and Kannangara, S. (2019). Morphological characterization and molecular identification of stem-end rot associated fungal species isolated from 'Karutha Colomban' mango fruits in Sri Lanka. Journal of Agricultural Sciences - Sri Lanka, 14(2), pp. 120-128.http://doi.org/10.4038/jas.v14i2.8514

Galsurker, O., Diskin, S., Maurer, D., Feygenberg, O. and Alkan, N. (2018). Fruit stem-end rot. Horticulturae, 4(4), pp. 50. https://doi.org/10.3390/horticulturae4040050

Herath, H., Dissanayake, M., Dissanayake, D., Chamikara, M., Kularathna, K., Ishan, M. and Sooriyapathirana, S. (2016). Assessment of the variations in selected industrially desirable morphological and biochemical traits of eleven citrus species in Sri Lanka. Procedia Food Science, 6, pp. 176-180.https://doi.org/10.1016/j.profoo.2016.02.043

Hillis, D. and Bull, J. (1993). An empirical test of bootstrapping as a method for assessing confidence in phylogenetic analysis. Systematic Biology, 42(2), pp.182.https://doi.org/10.2307/2992540

Kamhawy, M., Hassan, M., Sharkawy, S. and El-badawy, N. (2011). Morphological and phylogenetic characterization of Pestalotiopsis in relation to host association. Egyptian Journal of Agricultural Research, 89(1), pp. 1-16.https://doi.org/10.21608/ejar.2011.164990

Kaur, R., Kaur, J., Kaur, M., Kalotra, V., Chadha, P., Kaur, A. and Kaur, A. (2020). An endophytic Penicillium oxalicum isolated from Citrus limon possesses antioxidant and genoprotective potential. Journal of Applied Microbiology, 128(5), pp. 1400-1413.https://doi.org/10.1111/ jam. 14553

Khan, I., Ali, M., Aftab, M., Shakir, S., Qayyum, S., Haleem, K. and Tauseef, I. (2019). Mycoremediation: a treatment for heavy metal-polluted soil using indigenous metallotolerant fungi. Environmental Monitoring and Assessment, 191(10).https://doi.org/10.1007/s10661019-7781-9

Kimura, M. (1980). A simple method for estimating evolutionary rate of base substitutions through comparative studies of nucleotide sequences. Journal of Molecular Evolution, 16, pp. 111-120. https://doi.org/10.1007/bf01731581

Kodituwakku, T.D, Abeywickrama, K. and Karunanayake, K.O.L.C. (2020). Pathogenicity of stemend rot associated fungi isolated from Karthakolomban mango and their control by spray and fumigation treatments with selected essential oils. Journal of Agricultural Sciences - Sri Lanka, 15(1), pp.19-36.http://dx.doi.org/10.4038/jas.v15i1.8669

Ladaniya, M. (2008). Citrus fruit. Academic Press, London, UK.

Lazzizera, C., Frisullo, S., Alves, A. and Phillips, A. (2008). Morphology, phylogeny and pathogenicity of Botryosphaeria and Neofusicoccum species associated with drupe rot of olives in southern Italy. Plant Pathology, 57(5), pp. 948-956.https://doi.org/10.1111/j.1365-3059.2008.01842

Liu, Y., Heying, E. and Tanumihardjo, S. (2012). History, global distribution, and nutritional importance of citrus fruits. Comprehensive Reviews in Food Science and Food Safety, 11(6), pp. 530-545.http://doi.org/10.1111/j.1541-4337.2012.00201

Manghwar, H., Naz, S., Gul, S and Munis, M. (2015). First report of Rhizopus oryzae causing fruit rot of Citrus medica L. in Pakistan. Journal of plant pathology, 93(1), pp. 209-220. https://doi. org/10.4454/JPP.V97I1.035 
Muhammad, A., Mohammed, I., Ameh M., Bello, I., Haliru, B., Bagudo, H. and Sanda, A. (2018). Isolation and identification of fungi associated with the spoilage of sweet orange (Citrus sinensis) and banana (Musa sapientum) in Sokoto Metropolis. Journal of Applied Biotechnology \& Bioengineering, 5(3). https://doi.org/10.15406/jabb.2018.05.00135

Negi, S. and Anand, N. (2014). Supply Chain Efficiency: An insight from fruits and vegetables sector in India. Journal of Operations and Supply Chain Management, 7(2), pp. 154. https://doi. org/10.12660/joscmv7n2p154-167

Palou, L., Smilanick, J., Usall, J. and Viñas, I. (2001). Control of postharvest blue and green molds of oranges by hot water, sodium carbonate, and sodium bicarbonate. Plant Disease, 85(4), pp. 371-376. https://doi.org/10.1094/pdis.2001.85.4.371

Papoutsis, K., Mathioudakis, M., Hasperué, J. and Ziogas, V. (2019). Non-chemical treatments for preventing the postharvest fungal rotting of citrus caused by Penicillium digitatum (green mold) and Penicillium italicum (blue mold). Trends in Food Science \& Technology, 86, pp. 479-491. https://doi.org/10.1016/j.tifs.2019.02.053

Paul, D. and Shaha, R. (2004). Nutrients, vitamins and minerals content in common citrus fruits in the Northern Region of Bangladesh. Pakistan Journal of Biological Sciences, 7(2), pp.238-242. https://doi.org/10.3923/pjbs.2004.238.242

Ploetz, R.C. (2003). Diseases of tropical fruit crops. CABI Publishing, Wallingford, UK. pp. 327-364.

Qian, C., Fu, Y., Jiang, F., Xu, Z., Cheng, D., Ding, B., Gao, C. and Ding, Z. (2014). Lasiodiplodia sp. ME4-2, an endophytic fungus from the floral parts of Viscum coloratum, produces indole3-carboxylic acid and other aromatic metabolites. BMC Microbiology, 14(1). https://doi. org/10.1186/s12866-014-0297-0

Saroj, P. and Ambadas D. (2008). Post-harvest management of citrus fruits: A review. Journal of Food science and Technology, 45(3), pp 199-208.

Shravan, R., Shere, D.M. and Joshi, M. (2018). Study of physicochemical characteristics of sweet orange (Citrus sinensis) fruit. Journal of Pharmacognosy and Phytochemistry, 7(6), pp. 16871689.

Tafinta, I., Shehu, K., Abdulganiyyu, H., Rabe, A. and Usman, A. (2014). Isolation and identification of fungi associated with the spoilage of sweet orange (Citrus sinensis) fruits in Sokoto State. Nigerian Journal of Basic and Applied Science, 21(3): pp. 193-196. http://dx.doi.org/10.4314/ njbas.v21i3.4

Taha, Z., Howar, S. and Sulaiman, G. (2019). Isolation and identification of Penicillium italicum from Iraqi Citrus lemon fruits and its ability manufacture of silver nanoparticles and their antibacterial and antifungal activity. Research Journal of Pharmacy and Technology, 12(3), pp. 1320. https:// doi.org/10.5958/0974-360x.2019.00221.x

Tekpinar, A. and Kalmer, A. (2019). Utility of various molecular markers in fungal identification and phylogeny. Nova Hedwigia, 109(1-2), pp. 187-224.https://doi.org/10.1127/nova_ hedwigia/2019/0528

Timmer, L., Brown, G. and Zitko, S. (1998). The Role of Colletotrichum sp. in postharvestanthracnose of citrus and survival of C. acutatum on Fruit. Plant Disease, 82(4), pp. 415-418. https://doi. org/10.1094/pdis.1998.82.4.415 
Tripathi, P. and Dubey, N. (2004). Exploitation of natural products as an alternative strategy to control postharvest fungal rotting of fruit and vegetables. Postharvest Biology and Technology, 32(3), pp. 235-245. https://doi.org/10.1016/j.postharvbio.2003.11.005

Turner, T. and Burri, B. (2013). Potential nutritional benefits of current citrus consumption. Agriculture, 3(1), pp. 170-187. https://doi.org/10.3390/agriculture3010170

Wang, W., de Silva, D., Moslemi, A., Edwards, J., Ades, P., Crous, P. and Taylor, P. (2021). Colletotrichum species causing anthracnose of citrus in Australia. Journal of Fungi, 7(1), pp. 47. https://doi.org/10.3390/jof7010047

Zakaria, L. (2021). Diversity of Colletotrichum species associated with anthracnose disease in tropical fruit crops. Agriculture, 11(4), pp. 297. https://doi.org/10.3390/agriculture11040297

Zhai, L. and Zhang, M. (2019). First report of Neofusicoccum parvum causing fruit rot on Eriobotrya japonica in China. Plant Disease, 103(8), pp. 2125-2125. https://doi.org/10.1094/pdis-09-181511

Zhang, J. (2014). Lasiodiplodia theobromae in Citrus fruit (Diplodia stem-end rot). In: Postharvest decay. (Bautista-Banos, S. Eds.). Academic Press, USA. 309-335. https://doi.org/10.1016/ b978-0-12-411552-1.00010-7 